\title{
«¿̇Qué hubiera sido de mi vida sin el cine?». La experiencia cinematográfica en la Ciudad de México
}

\author{
Jerónimo Repoll \\ (Universidad Autónoma de la Ciudad de México) \\ Maricela Portillo Sánchez \\ (Universidad Iberoamericana, Campus Santa Fe, México) \\ Philippe Meers \\ (Universidad de Amberes, Bélgica)
}

Recibido: $7 / 4 / 2014$

Aprobado: 3/6/2014

\begin{abstract}
RESUMEN: En el presente artículo, exploramos la experiencia cinematográfica en la Ciudad de México, teniendo como referente a la oferta fílmica, pero no limitándonos a ella. Ampliamos la mirada, entonces, a la histórica, cultural y social del cine, anclada en los usos y apropiaciones. De esta manera, enmarcados en la perspectiva de los estudios culturales, esta investigación constituye un particular estudio de recepción, afianzado en la memoria (siempre selectiva) de los espectadores de cine. Al mismo tiempo, es necesario señalar que este artículo es fruto de una investigación más amplia.
\end{abstract}

Palabras clave: cine / experiencia cinematográfica / Ciudad de México / comunicación / estudios culturales

\section{"What would have become of my life without cinema?»: Cinematographic experience in Mexico City}

SumMary: In this paper we explore the cinematogragphic experience in Mexico City, taking as a reference to the film offer but not limited to it. We extend the look, then, to the cultural and social history of film, anchored in the uses and appropriations. Thus framed in the perspective of cultural studies, this research study is a particular reception anchored in memory (if selective) of moviegoers. At the same time, it should be noted that this article is part of a wider investigation.

Key words: cinema / cinematic experience / Mexico City / communication / cultural studies 
En la capital, especialmente, el cine es mucho más que «fábrica de sueños»; es la escuela de las psicologías individuales, es la visión de lo deseable.

Monsiváis ${ }^{1}$

$\mathrm{E}$ ste artículo se deriva del proyecto «Cultura de la pantalla: entre la ideología, la economía política y la experiencia. Un estudio del rol social de la exhibición cinematográfica y su consumo en Ciudad de México, México (1896-2010), en interacción con la modernidad y la urbanización», réplica para la Ciudad de México del estudio original ${ }^{2}$ desarrollado en las ciudades de Gante y Amberes, Bélgica, y antes replicado en Monterrey, México. Este proyecto sigue la misma aproximación teórico-metodológica, desde la cual se pretende realizar un inventario de las salas de cine, un análisis de contenido de la cartelera cinematográfica y el estudio del consumo cinematográfico en la Ciudad de México durante el siglo $\mathrm{XX}$, incluyendo finales del siglo XIX e inicios del XXI.

La investigación tiene proyectado concluirse en tres años. Dado que nos encontramos en la primera fase de su desarrollo, presentaremos resultados preliminares respecto del consumo cinematográfico en interacción con la modernidad y la urbanización en la Ciudad de México. Para ello, trabajamos desde una perspectiva cualitativa, realizando entrevistas en profundidad y siguiendo un cuestionario semiestructurado a tres grupos distintos de edad (20-40; 41-60; 61 en adelante), hombres y mujeres, correspondientes a dos clases socioeconómicas (media baja y media alta). El objetivo final del estudio es reconstruir la cultura de pantalla y, en esta ponencia, discutiremos, de manera puntual, la experiencia social de ir al cine.

Esta investigación, además de constituir una réplica del estudio de Meers, Biltereyst y Van de Vijver (2010), reconoce como antecedentes los trabajos de Staiger (1992), Kuhn (1999) y Allen (2006), entre los más destacados aportes en la corriente del new cinema history o nueva historia cinematográfica, la cual subraya la importancia del espacio, el lugar y la sociabilidad como rasgos constitutivos de la experiencia cinematográfica. Esto supone un desplazamiento de la historia cinematográfica centrada en el análisis de las películas.

De esta manera, la investigación se encuadra en la perspectiva de los estudios culturales, considerando a la producción de sentido como fruto de múltiples condicionantes, tanto estructu-

1 1994, p. 21.

2 «Screen culture: between ideology, economics and experience. A study on the social role of film exhibition and film consumption in México (1895-1992) in interaction with modernity and urbanization». 
rales como subjetivos, los contextos específicos y las situaciones en las que se establecen las interacciones con los medios, en general, y con el cine, en particular. En este marco, seguimos el modelo de «consumo fílmico en contexto» (Meers, 2010) que busca:

Esbozar los mapas de ruta de las tensiones cruciales entre los intereses comerciales de la exhibición de cine contra las apropiaciones de los espectadores, las dimensiones ideológicas de los contenidos cinematográficos y las lecturas de ellos por parte de los asistentes al cine, así como las experiencias mediáticas entre lo público y lo privado (Lozano et al., 2011, p. 1).

En este caso, se busca comprender la experiencia cinematográfica en la Ciudad de México a lo largo del siglo $\mathrm{XX}$, entendiendo a la ciudad como algo más que contexto y la recepción cinematográfica como algo más que consumo cultural. Es decir, el cine nos permite pensar la ciudad, tanto como esta nos permite pensar el cine ${ }^{3}$.

Explorar la memoria (que siempre supone una reconstrucción del pasado) constituye un particular estudio de recepción. Así, este es un estudio que tiene como referente la experiencia cinematográfica, conteniendo en ella la oferta fílmica, pero no limitándose a ella. Amplía la mirada, entonces, a la histórica, cultural y social del cine, anclada en el espectador, sus usos y apropiaciones. Un desplazamiento similar había ocurrido tiempo atrás en los estudios sobre audiencias de televisión, pasando de la inferencia de la audiencia inscrita en los textos a una audiencia activa, situada económica, social, cultural e ideológicamente. Un análisis más amplio del desplazamiento del texto al contexto puede verse en Arqueología de los estudios culturales de audiencia (Repoll, 2010). Por otro lado, estos estudios empatan con la noción de cinevidencia, la cual se propone como una traslación del concepto de televidencia desarrollado por Orozco (1996), en el cual se reconoce que la recepción no se limita al momento de la exposición (en este caso, cinematográfica), sino que es un proceso de producción social de sentido, que comprende un antes, durante y después, un proceso abierto a múltiples actualizaciones, articulando las experiencias de ir al cine en el transcurso de la vida cotidiana, lo cual puede evidenciarse a través de explorar la memoria de los espectadores (Staiger, 1992, 2000).

3 El cine como un fenómeno multidimensional que va mucho más allá de su lógica comercial, pero que desde una lógica industrial comprende los procesos de producción, distribución, exhibición y consumo. Y que, desde una lógica sociológica, puede asumir el papel de instrumento de dominación ideológica tanto como el de subversión (denuncia) de un orden determinado; permite, desde el consumo, diferenciar las clases sociales; es fuente de entretenimiento tanto como herramienta pedagógica, formadora de ciudadanía y educadora sentimental. 
En esta línea, destaca el trabajo de Kuhn (1999), en el cual explora la memoria de la experiencia de ir al cine en la década de 1930 en Gran Bretaña, a través de la historia oral (generada por medio de entrevistas en profundidad) y una encuesta postal (con una muestra autoseleccionada) que resultó en 186 cuestionarios devueltos. De los diversos resultados de la investigación cabe destacar que, más allá del recuerdo de algunas películas y estrellas de la década de 1930, el recuerdo más significativo emerge en torno al entrelazamiento de la práctica de ir al cine con la vida cotidiana. Así, el ir al cine era una más de un conjunto de actividades sociales, relacionadas con las interacciones con la familia y amigos, así como los recorridos por la ciudad (del barrio al centro). Ir al cine, concluye Kuhn, era parte de la vida diaria, una actividad fácil, placentera, alegre y todavía recordada con cariño.

Incorporándonos en esta tradición, compartimos con Morley el interés por las

'historias íntimas' de cómo vivimos con medios tan distintos. Una cuestión importante en este sentido es cómo nuestros recuerdos personales, sobre todo de la infancia, son formulados en torno a experiencias con los medios, como los programas y los personajes emblemáticos de la televisión [o el cine] (Morley, 1998, p. 128).

Realizar una réplica del estudio original siempre es un desafío, pero tratar de dar cuenta de la experiencia cinematográfica en la Ciudad de México, acumulada a lo largo de un siglo, constituye una empresa de alto riesgo. Mientras Monsiváis describe una ciudad que entre 1920 y 1960 es ya «inabarcable, al borde de la magna explosión demográfica, aun tradicionalista, ya en tratos firmes con la modernidad, nacionalista por necesidad, cosmopolita según quienes sean los arquitectos» (1994, p. 7), García Canclini, para la segunda mitad del siglo XX, la describe como megalópoli, señalando que

cuando se afirma de la Ciudad de México que es varias ciudades, suele aludirse a la dificultad de abarcar su diseminación territorial, la heterogeneidad de barrios residenciales, zonas industriales y administrativas, comerciales y universitarias, antiguas y modernas (1998, p. 19).

Este, sin duda, constituye uno de los grandes desafíos en la adecuación y concreción de los objetivos del proyecto de investigación pensado originalmente no solo en otro contexto sociocultural, sino también desde ciudades que poco tienen que ver con una megalópolis como la Ciudad de México.

Esta apuesta, sin embargo, vale la pena si consideramos con Monsiváis que:

En sus más de cien años de vida, el cine latinoamericano le ha sido esencial a millones de personas que a sus imágenes, relatos y sonidos deben en buena medida sus acervos de lo real y de lo fantástico. No obstante el predominio del cine norteamericano, las 
variantes nacionales en América Latina han conseguido a momentos una credibilidad inmensa (2000, p. 51).

Para ello hemos constituido un equipo de investigación interinstitucional, coordinado por Maricela Portillo (Universidad Iberoamericana), Vicente Castellanos (Universidad Autónoma Metropolitana-Cuajimalpa) y Jerónimo Repoll (Universidad Autónoma de la Ciudad de México), articulados con el proyecto internacional coordinado por Meers, Biltereyst y Lozano, de las universidades de Amberes, Gante (Bélgica) y Laredo (Estados Unidos), respectivamente. Para la investigación «Cultura de pantalla» en la Ciudad de México, contamos con la colaboración de colegas y tesistas asociados de las instituciones mencionadas.

\section{Consumo y diferenciación social}

Hasta la década de 1960, la asistencia al cine era masiva y transclasista. Si bien en un inicio «la mezcla de los diversos sectores fue inevitable: 'el cinematógrafo juntaba a ricos y pobres, no jerarquizaba'» (Rosas, 2006a, p. 389), conforme se construyen los grandes palacios (las salas del «centro») y crecen como hongos los cines de «barrio», el consumo de cine, como cualquier otro consumo (Bourdieu, 1999), describe un proceso simbólico de diferenciación social.

En estos años, la taquilla no es solo espejo de tendencias del gusto. Es sobre todo el instrumento que jerarquiza estilos, modas, energías (Monsiváis, 1994, p. 22).

A partir de las recurrentes crisis económicas, aunadas a la irrupción de la televisión, la asistencia a las salas de cine decrece significativamente, experiencia que parecía destinada a desaparecer con la incorporación de la tecnología de registro, distribución y consumo del video. Al dar cuenta de este proceso, García Canclini (1994) acuña la noción de espectadores multimedia, los cuales consumen cine indistintamente en salas o en sus casas. Este proceso, acentuado por la digitalización que ha revolucionado el circuito completo de las industrias culturales (producción, distribución y consumo), ha significado un consumo ampliado y a la carta, diversificado en torno a múltiples plataformas y pantallas, que continúa subrayando la diferenciación social a través del acceso a consumos cada vez más sofisticados.

No obstante las nuevas posibilidades de consumo y después de haber tocado fondo, a mediados de la década de 1990, tanto la producción como el consumo cinematográfico en México describen una tendencia al alza, coincidiendo con la construcción de centros comerciales que integraron complejos multipantalla. Respecto de la asistencia al cine, la información de la Cámara Nacional de la Industria Cinematográfica y del Videograma (Canacine) indica un incremento sostenido en los últimos años, como puede observarse en el siguiente gráfico: 
Jerónimo Repoll, Maricela Portillo Sánchez, Philippe Meers

Gráfico 1

Número de asistentes al cine en México

(millones)

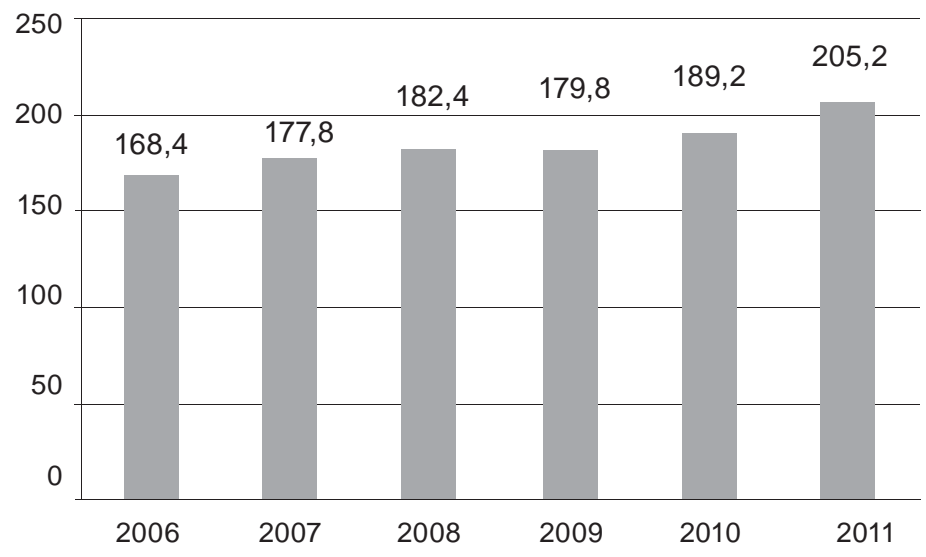

Fuente: Canacine.

Gráfico 2

Número de pantallas en México

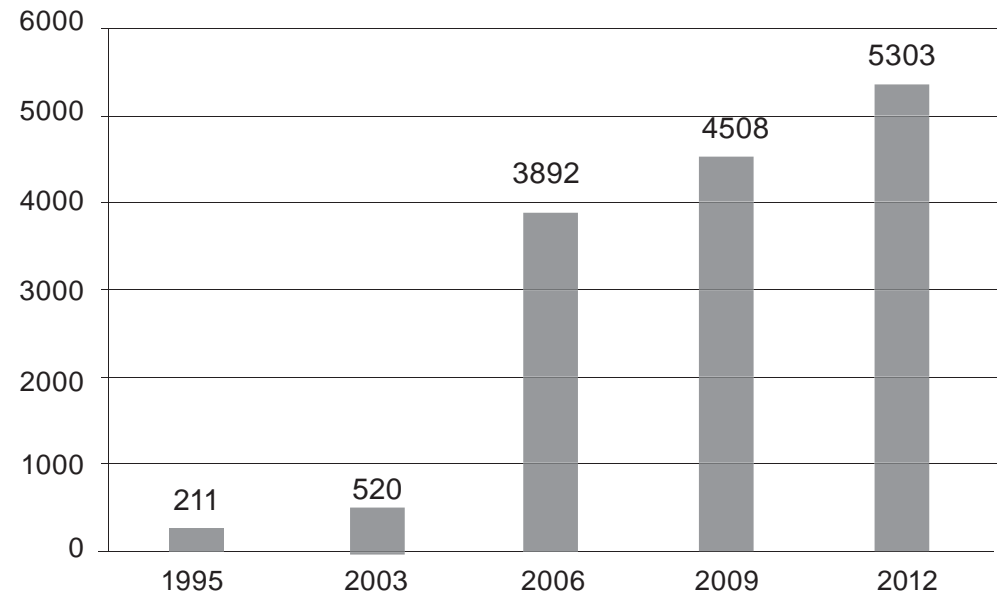

Elaboración propia, con datos de Canacine e Imcine. 
Pese a este crecimiento en la cantidad de pantallas (véase el gráfico 2) y en la asistencia a las salas de cine, la cuota de pantalla del cine mexicano no se amplía respecto a las producciones extranjeras ni el consumo es igual para todos los sectores sociales. Al contrario, confirmando la tendencias identificadas por Rosas (2006a) respecto de las diferencias en la frecuencia de asistencia al cine entre sectores altos, medios y populares, Gómez (2009) y Fuertes (2013) coinciden en señalar que el consumo de cine es cada vez más selecto, describiendo un proceso de «elitización». Así, «más que un espacio público que favorezca la interacción y la integración por el encuentro de los diversos -interactivo, significativo, multicultural, democrático, según lo ha definido Jordi Borja-, se trata de espacios no inclusivos, diferenciados, que contribuyen a la fragmentación y la exclusión social» (Rosas, 2006b, p. 320).

En función de esta tendencia positiva en términos de incremento de número de salas y de asistencia de espectadores, vale recuperar para la presente discusión la reflexión de Russo cuando señala que uno de los ámbitos donde se asienta el relato sobre la muerte del cine:

Se vincula con la pérdida de un lugar central para la experiencia cinematográfica dentro del mundo contemporáneo, desplazada hacia un lugar subsidiario y crecientemente minoritario dentro del omniabarcativo complejo de lo audiovisual [...]. Seriamente ame- nazado desde mediados de siglo, en principio por diversas modificaciones demográficas - como la suburbanización de las clases medias en sociedades como la estadounidense- y luego reforzado por el consumo hogareño de lo televisivo, el hecho de «ir al cine» pasó de ser algo central y de popularidad indiscutida, a convertirse en una práctica más segmentada, orientada a públicos crecientemente parcializados, hasta lo minoritario (Russo, 2009, pp. 141-142).

Esta «exclusividad» en el consumo de cine, que es otra forma de nombrar la desigualdad (y la distinción) social, se ahonda cuando observamos la distribución porcentual de la asistencia por Estado, donde la Ciudad de México tiene una cuota del $27,6 \%$; seguido por Nuevo León con 7,6 \% y Jalisco con 6,8 $\%$. El resto de los estados tienen un porcentaje raquítico, el cual es más angustiante cuando comparamos las ciudades capitales con otros municipios del mismo estado. Lo mismo sucede si desagregamos el dato promedio de cinco pantallas por cada 100000 habitantes.

Ahora bien, como señalamos antes, el consumo de cine se ha ampliado a múltiples pantallas, siendo su otrora principal competidora, la televisión, la plataforma a través de la cual se lo consume significativamente. Así lo reporta el Obitel en los cinco informes que ha presentado desde el año 2007. Si bien la ficción no ocupa un lugar preponderante en la programación televisiva, en este campo el cine es, en promedio, el $50 \%$. A saber: en 2007 , el $15 \%$ ficción general, el $16 \%$ cine; en 
2008, el 18 \% ficción general y el $20 \%$ cine; en 2010, el 15 \% ficción general y el 12 \% cine; en 2011: el $16 \%$ ficción general, el 11 \% cine; en 2012, 14 \% ficción general, el $13 \%$ cine.

A esto debemos sumarle internet y sus múltiples plataformas, ya sean «gratuitas», como YouTube, o de paga, como Netflix. Para no extendernos, presentamos cuatro imágenes a través de las cuales esta plataforma se publicita (en su propia página web), descri- biendo la experiencia de consumo tal como ellos la conciben, reconociendo las características y necesidades del nuevo espectador.

Cuatro pantallas; en soledad, con hermanos, en familia; en espacios interiores y exteriores; espacios privados o compartidos; de día o de noche; para hombres y mujeres, relativamente jóvenes y con marcados rasgos étnicos; $\mathrm{y}$ todos felices.
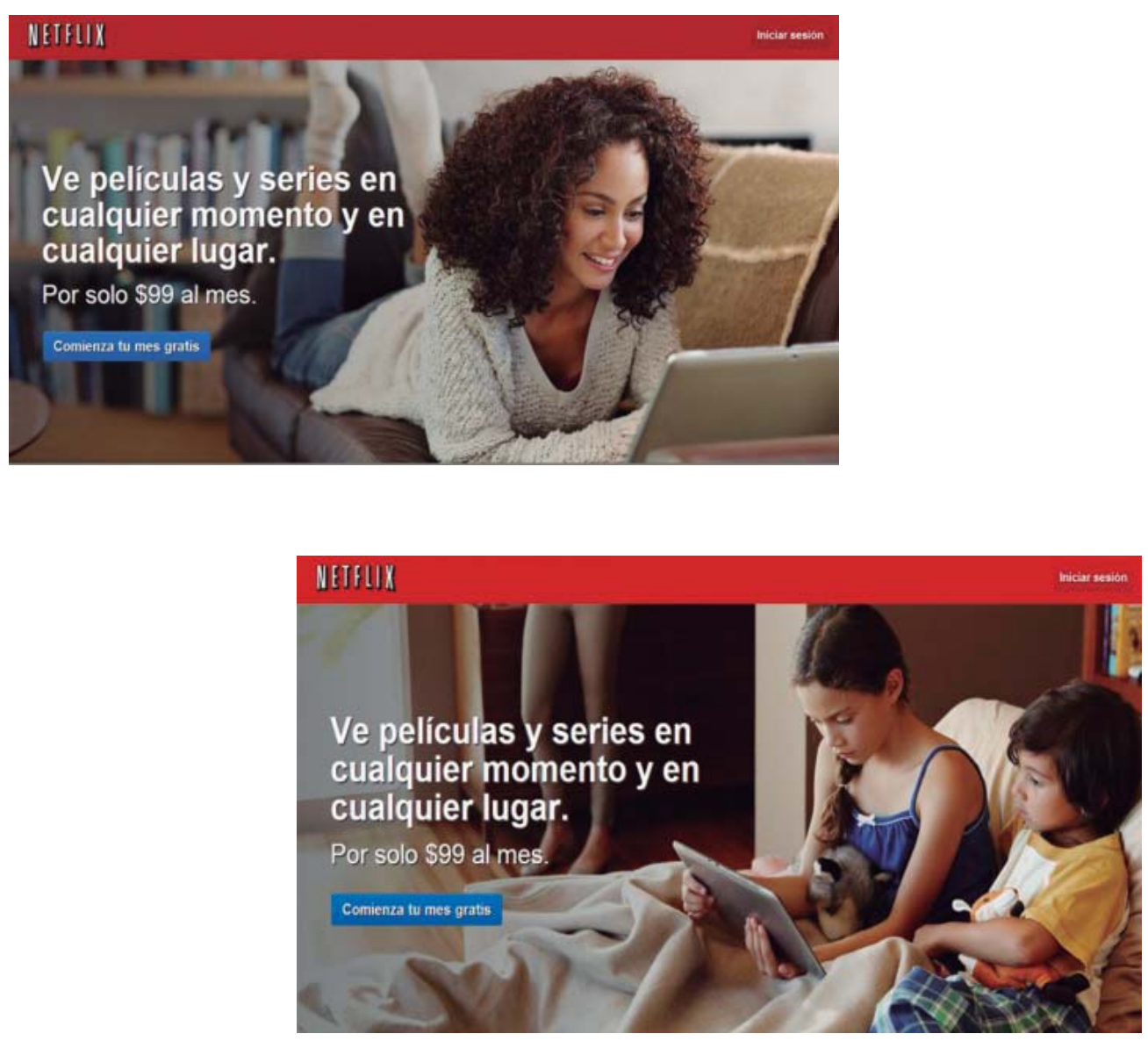

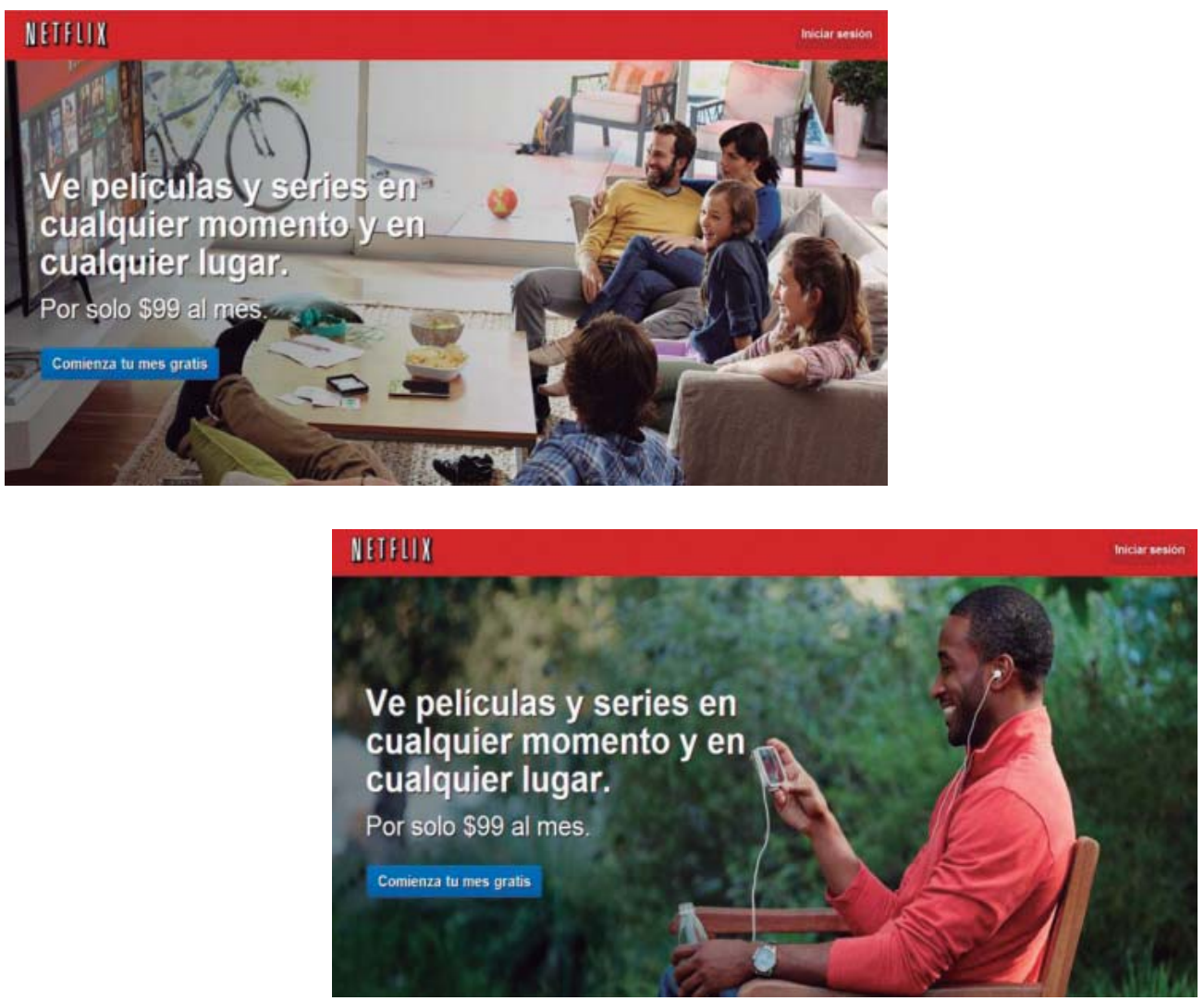

\section{Del consumo a la experiencia cinematográfica. Resultados preliminares}

Hasta el momento se han realizado veintiocho entrevistas de un total perseguido de noventa. En tal sentido, si bien no podemos sacar resultados concluyentes, sí tenemos una serie de elementos que vale la pena analizar y discutir. De entrada, volvemos a subrayar este ir más allá de los datos cuantitativos de consumo, no porque no sirvan (ya sea al mercado, en térmi- nos de audiencias; o al Estado, de cara a diseñar políticas públicas), sino porque nos interesa conocer el otro lado, el de la experiencia de los espectadores a lo largo de toda su vida, articulada con el desarrollo urbano de la ciudad y el proceso de modernización que ha seguido (aunque nunca en línea recta, como sabemos en América Latina).

Un primer elemento que destacar es la dificultad metodológica para establecer con nitidez la distinción entre las clases. En tal sentido, la distinción por el consumo, pese a sus limitacio- 
nes, combinada con las variables sociológicas nos permiten ubicar a estos dos sectores de espectadores: clase media alta y clase media baja. Aquí tratamos de recuperar y ubicar a los espectadores en términos socioeconómicos y culturales. En tal sentido, el enclasamiento es una operación metodológica posterior a la realización de la entrevista, es decir, fruto del análisis de la entrevista.

Ahora bien, como se trata de una réplica, uno de los problemas metodológicos al que nos hemos enfrentado es que los cuestionarios semiestructurados, que buscan establecer elementos constantes para permitir la comparación de resultados entre ciudades, aporta una información limitada. En tal sentido, sin desatender tendencias y regularidades, en el presente estudio se apuesta por una entrevista en profundidad, de carácter antropológico, que cubra los indicadores del cuestionario base, pero que dé tiempo y lugar para explorar aspectos singulares de cada entrevistado, en pos de recuperar la experiencia cinematográfica.

A partir de aquí, vamos tejiendo algunos testimonios (provenientes de las entrevistas) con breves interpretaciones de los investigadores:

Era todo en blanco y negro. Hicieron una de Semana Santa donde precisamente salía ese actor Ramón Novarro, mexicano, pero hecha en Estados Unidos, pero muy mal coloreada, completamente mal, mal, estaba... (era mudo el cine). Ya empezaba... empezó en
1930 o 31 el cine sincronizado, y ponían los... daban programas de papel de ese delgadito y largos así, con unas letrotas sincronizado y yo iba y no oía nada y le decía a mi hermana, pues cuál, si yo no oigo nada, ¿pues no oíste que taconeó la muchacha?, ah, pues sí oí, pero a mí se me figuraba que se... (ponían el disco y la película se sincronizaba... a veces iba más... se veía la diferencia, se adelantaba la película o se atrasaba, entonces el sonido llegaba más tarde). A veces se callaba y nada más veía uno a los actores que movía la boca; sí, pues, tenía sus imperfectos todavía y más como ese cinito que se llamaba Hollywood y era muy querido por toda la colonia, era el Holly... entonces era pues este... un cine de barrio que no costaba caro, que era barato y entonces les fallaban muchas cosas (Amelia, 61 +, clase media alta).

Este testimonio, correspondiente a la persona de más edad hasta ahora entrevistada (93 años), constituye en sí mismo un documento invaluable. Recuperar la experiencia cinematográfica desde la perspectiva del espectador y no del cronista de la época, de las descripciones publicadas en la prensa o de reflexiones de intelectuales, las cuales tienen un valor específico, pero siempre asumiendo una lectura sesgada de lo que ahí estaba pasando. Como ejemplo ilustrativo podemos recuperar al mayor especialista en la crónica de los espectáculos populares, Carlos Monsiváis:

En el cine de barrio se adquiere algo fundamental, que ayuda a vivir dentro de la ciudad que se expande: el 
sentido de intimidad dentro de la multitud y su complemento: el gusto de afiliarse a la alegría comunitaria. En el período 1920-1960 las salas de cine se multiplican y ayudan a configurar «la identidad del barrio», mientras cada fin de semana los individuos y las familias esmeran sus ilusiones, y las parejas afinan ligues o noviazgos en el trámite casi burocrático de manos que suben, se estacionan, se aceleran, se indignan ante forcejeos inoportunos, se extasían ante rendiciones instantáneas. «Lo que con los ojos veo con las manos adivino» (1994, p. 20).

Este aspecto es el más distintivo de todo el estudio, hecho por el cual hemos priorizado entrevistar a personas de la generación que tienen 61 años y más, considerando dos aspectos contundentes: la muerte o la pérdida de memoria por enfermedad. Ambos acontecimientos, ambos lamentables, constituyen no solo la pérdida de un testimonio para la investigación, sino el registro de la memoria de una etapa fundamental que no es únicamente para el cine, sino para el desarrollo de la ciudad en su conjunto.

En la misma categoría que la anterior entrevistada, pero mucho más joven (64 años), Janina, en la infancia, asistía al cine con sus padres y ellos decidían qué ver; en la juventud, iba con sus amigos y decidían entre todos. Las salas eran las mismas: Universidad y Manacar. Ya de adulta, asiste con sus hermanos o amigos al mismo cine. Es decir, su experiencia cinematográfica se vincula con una sala a lo largo de toda su vida, cercana a su casa, en la colonia Del Valle (clase media alta, escolarizada hasta el nivel universitario). Por su edad, clase social y lugar de residencia, no tiene una experiencia significativa respecto de los «cines de barrio»:

Lo que pasa es que como son consorcios, entonces, haz de cuenta que de cines así chiquitos me acuerdo que en la prepa nos llevaban. Nos mandaron de tarea ir a ver Naranja mecánica entonces así como que eran los cines más feos y más rascuachos que había, pero fuera de eso, más bien vamos a las cadenas (Janina, 61 +, clase media alta).

En cierto sentido, las cadenas de salas de cine también homogenizan la experiencia cinematográfica. La cinematografía norteamericana es la que rememora a lo largo de toda su vida. De las princesas Disney a Travolta o Clooney.

Esta experiencia de la ciudad también nos plantea la vivencia en una ciudad reducida. La Ciudad de México son muchas ciudades en una, aquí recuperamos la ciudad vivida/relatada por los espectadores de cine.

En Plaza Universidad subes y arriba es donde están las salas, abajo están las tiendas y arriba las salas de cine (Janina).

Como podemos ver, Janina no solo tiene una experiencia centrada en el consumo de cine estadounidense, habiendo asistido a las mismas salas durante toda su vida, sino que tam- 
bién nos habla del consumo ampliado, donde ir al cine es ir al centro comercial. Una experiencia, como hemos señalado más arriba, que tiende a un determinado tipo de consumidor, con un poder adquisitivo que le permita comer, ir de compras y al cine en el mismo lugar.

Mira... para mí el cine, y lo que primero que vi (que fue muy impactante), esa forma (ahora ya con la experiencia que tengo y todo), esa forma de ver cómo presentan esas películas, con dos niños que sacan un libro de la basura, así era nuestra vida. $\mathrm{Y}$ así como se ve en esa película, eso era lo que se vivía, al menos en donde nosotros vivíamos, era lo que se veía: esa pobreza, que el carpintero, el que era el riquillo, el que era el malo, la que se dormía de día, todo eso lo vivíamos en vivo nosotros, muy parecido, entonces, para mí fue como retratar en el cine lo que estábamos nosotros viendo, viviendo. Fue muy parecido. Y luego cuando entro a trabajar..., bueno, yo me quedé con hambre de ver mucho cine, la verdad. Sí, yo quería ir muy seguido al cine. En primera, no nos dejaban y, en segunda, no había las posibilidades. Luego me caso con un señor que me tiene acá y que hubiera dicho: oye, vete con mis hermanas al cine y yo me quedo con los niños, pues no. O vete tú y yo me quedo con los niños. No había esa posibilidad ni él era tan abierto... por eso, ahora soy felizmente libre (Georgina, $61+$, clase baja).

A diferencia de las anteriores, Georgina (74 años) nos presenta un relato que teje la experiencia cinemato- gráfica con la pobreza de la vida cotidiana. No solo se trata de identificarse con la trama de una película como Nosotros los pobres o Ustedes los ricos, sino también de cuestionar las condiciones de vida, los logros personales (saber de dónde salió y hasta dónde llegó). Al ser su primera experiencia subraya que:

Lo recuerdo mucho y me gusta mucho Pedro Infante, pero yo como mamá no lo haría, de llevar a ver a mis hijos... y menos como premio a ver todo lo que sufrí. Era llorar y llorar y llorar (Georgina).

$\mathrm{Al}$ respecto, aunque es una entrevista que tiene mucho que cortar, recuperamos un pasaje de su testimonio donde recuerda con claridad meridiana el costo de las entradas, los días que había promoción y la sala a la que acudía. Esto nos ubica en torno a las necesidades, prioridades y conciencia del costo de la vida en un entorno de clase baja en la Ciudad de México. Un entorno para el cual el cine era un lujo y constituía un objeto/práctica de deseo:

Después íbamos mucho al cine Estrella, ya cuando yo empecé a trabajar. Pues igual, mi mamá nos decía: «Nos vemos en el cine Estrella. Los jueves, que también pagaba uno más barato. Y daban dos películas, pero esas eran norteamericanas. Hace un tiempo era los miércoles, pero antes era los jueves cuando la función era más barata. Siempre había tres por 2 pesos. Allí, en el cine Estrella, creo que eran tres 
películas, o dos películas, según fueran las horas que durara una película, eran 2 o 3 pesos. Muchos años duró el cine costando 2 pesos.

Sí. Para nosotros era un lujo. Luego mis hijos se ríen, pero era un lujo ir al cine. Y además todo el día andábamos emocionadas, ya queríamos comer para irnos al cine. Y eran unas colas. Sobre todo en las películas de Pedro Infante, aunque estuvieran pasándose en varios cines y mucho tiempo, duraban en cartelera meses y meses, y eran las colas que daban vuelta. No, no, no, espantoso (Georgina).

A diferencia de Georgina, no solo por la edad, sino también y especialmente por la clase social a la que pertenece, Dafne (41-50) subraya la dimensión ritual del consumo de cine, cuando relata que durante su infancia: «Después de que acabábamos, mi papá nos llevaba a comprar helado y ya después íbamos a la casa» (Dafne).

Es interesante, en términos de clase, que al interrogar a las personas de clase media alta, estas no tienen registro de crisis alguna, de problemas económicos o políticos (al menos durante la infancia, un momento de vivencia más que de racionalizaciones). En este sentido, se infiere una infancia al margen de los problemas sociales. Esto marca diferencias notables con los entrevistados que pertenecen a una clase media baja, donde el recuerdo del precio del boleto y lo que implicaba ir al cine acompañan el relato de las carencias cotidianas.
Al mismo tiempo, es reconocida como típica la situación en la que los compañeros de escuela hablan de las películas que vieron el fin de semana, preguntando a otros si ya las vieron. En tal sentido, aquí encontramos una pista de cómo el consumo de cine (entre otros) constituye un elemento de sentido común, en el sentido de compartir referentes y desarrollar prácticas de ocio que extienden el compartir el espacio escolar. Claro, no podemos estimar el peso de esta práctica común de consumo cultural respecto de otros consumos: televisivo, deportivo, etc. (espectador multimedia). Si el condicionamiento del cuestionario establecido para esta investigación nos impide acceder a dicha información con sujetos socializados durante el reinado de la televisión, mucho más difícil resultará establecer el peso de cada actividad en un entorno transmediático, donde las narrativas se expanden en múltiples plataformas, e incluso nacen con la intención de desarrollarse a través de ellas.

Otra diferencia importante, ya no de clase, sino de generaciones de entrevistados, son que las que corresponden a 61 años y más tenían mucho más autonomía para ir al cine durante su infancia que la que tuvieron las siguientes. Aquí puede plantearse la hipótesis en torno a los condicionantes de la ciudad. Así como las generaciones más jóvenes prácticamente desconocen la experiencia del cine de 
barrio, para las primeras hay una notable diferencia, vivida en su infancia, entre los cines de barrio y los cines del centro. De hecho, el paso de la infancia a la juventud, que la generación de 61 años y más establece en torno al inicio de la vida laboral a temprana edad (en torno a los quince años), constituye también el acceso frecuente al centro de la ciudad, que era el espacio laboral por antonomasia, y con él a los cines más importantes de la ciudad, a los «palacios»y no a los «cinitos».

En este sentido, también hay una nostalgia del tiempo pasado, asociado al cine, en la generación de 61 años y más. Lo que podríamos establecer como el síndrome Cinema Paradiso.

Otros dos lineamientos en términos de género: la articulación entre la oferta y el género en la etapa de infancia, donde es prácticamente exclusiva la oferta norteamericana. Cine de princesas y cine de aventuras/caricaturas para niñas y niños, respectivamente.

También encontramos, en las generaciones de clase media alta, la respuesta del deber ser en torno a la migración de las cadenas comerciales (y la oferta norteamericana) a espacios como la Cineteca Nacional (y la oferta de cine de arte).

Respecto de la relación con el consumo familiar, tenemos una suerte de olas, donde el consumo está marcado por la oferta cinematográfica infantil. Más allá de quién decide (padres o hijos), en la infancia van con los padres, se alejan en la juventud y retornan en su vida adulta como padres.

Para cerrar, en lugar de concluir citamos a otro entrevistado, cinéfilo, el cual sintetiza el espíritu de la investigación y apunta la potencialidad de la misma:

Yo soy cinéfilo, amo el cine y me he preguntado muchas veces, no de ahora que me ibas a entrevistar, sino desde hace tiempo: ¿qué hubiera sido de mi vida sin el cine?, ¿cómo sería yo?, ¿qué clase de persona sería yo? No estoy a disgusto conmigo, estoy a gusto conmigo, pero pienso yo que parte de estar a gusto conmigo mismo se lo debo al cine, ¿cómo ves? (Jorge Trejo, 78 años, clase media baja).

\section{Consideraciones finales}

Concluimos con estas consideraciones que se desprenden de los resultados presentados en este análisis preliminar:

- La experiencia cinematográfica en primera persona: pasamos del análisis del consumo en términos cuantitativos a la perspectiva vivida por los propios espectadores. Aquí es significativo subrayar que la memoria implica una reconstrucción selectiva del pasado, desde donde se resignifica la vida cotidiana de los espectadores y de la ciudad.

- Explorar la cultura de pantalla a lo largo del siglo XX nos permite pensar su articulación con el pro- 
ceso de desarrollo urbano, la modernización y la construcción de ciudadanía.

- Dos variables emergen, de momento, como las más significativas a la hora de establecer recurrencias y comparaciones en los testimonios: la clase social y la generación a la que se pertenece. Hay indicios menos fuertes en torno a la variable de género.

- Se confirman los datos de consumo cultural respecto del cine como diferenciador social.

- La concepción de la ciudad, articulada a partir del recuerdo de la experiencia con los cines de barrio o los palacios, ubicados en el centro, nos permiten desandar los trayectos y las rutinas cotidianas a lo largo del siglo XX.

\section{Referencias}

Allen, R. (2006). Relocating American Film History. The «Problem» of the Empirical. Cultural Studies, 20 (1), 48-88.

Canacine (2011). Asistencia al cine en México. Datos básicos. Resultados 2011. Recuperado de http://canacine.org. mx/index.php/resultados-2011/asistencia-al-cine-en-mexico.html

Fuertes Martínez, M. (2013). La cinematografía mexicana como industria cultural. Una revisión de sus políticas y de su mercado desde la década de los ochenta. En D. Cro- vi, (Coord.), Industrias culturales en México. Reflexiones para actualizar el debate (pp. 301-341). México, D. F.: Tintable.

García Canclini, N. (1994). Los nuevos espectadores. Cine, televisión y video en México. México, D. F.: Conaculta, IMCINE, DGP.

García Canclini, N. (1998). Las cuatro ciudades de México. En N. García Canclini (Coord.), Cultura y comunicación en la Ciudad de México (pp. 1939). México D. F.: Grijalbo, UAM-M.

Gómez García, R. (2009). La industria audiovisual mexicana: estructura, políticas y tendencias. Conexiones, 1 (1), 77-92.

Imcine (2012). Anuario estadístico de cine mexicano. México, D. F.: Imcine.

Lozano, J., \& Frankenberg, L. (2012). Memories of Films and Cinema Going in Monterrey, Mexico: A critique and review of in-depth interviews as a methodological strategy in audience studies. En A. Valdivia (Ed.), Blackwell's International Companion to Media Studies: Research Methods in Media Studies. Volume Editor: Fabienne Darling-Wolf. Oxford: Blackwell.

Meers, P., Biltereyst, D., \& Van de Vijver, L. (2010). Metropolitan vs Rural Cinemagoing in Flanders, 19251975. Screen, 51 (3), 272-280.

Monsiváis, C. (1994). Luneta y galería. Atmósferas de la capital 1920-1959. México, D. F.: Departamento del Distrito Federal. 
Monsiváis, C. (2000). Aires de familia. Cultura y sociedad en América Latina. Barcelona: Anagrama.

Repoll, J. (2010). Arqueología de los estudios culturales de audiencia. México, D. F.: UACM.

Rosas Mantecón, A. (2006a). Consumo cultural y diferenciación social: ir al cine en la Ciudad de México 1930-2003. En T. Páramo (Coord.), Sociedad y comunicación. Una mirada al siglo XXI (pp. 289-404). México, D. F.: UAM-I y Plaza y Valdés.

Rosas Mantecón, A. (2006b). Las batallas por la diversidad: exhibición y públicos de cine en México. En G.
Sunkel (Coord.), El consumo cultural en América Latina (pp. 318-341). Bogotá: Convenio Andrés Bello.

Russo, E. (2009). Las tres muertes del cine: algunas hipótesis sobre un discurso recurrente. En M. Carlón \& C. Scolari (Eds.), El fin de los medios masivos. El comienzo de un debate (pp. 137-156). Buenos Aires: La Crujía.

Staiger, J. (1992). Interpreting Films: Studies in the Historical Reception of American Cinema. Princeton, NJ: Princeton University Press.

Staiger, J. (2000). Perverse Spectators: The Practices of Film Reception. Nueva York: New York University Press. 